\title{
AMYL NITRITE INDUCED CHANGES IN CARDIAC SHUNTS
}

\author{
BY \\ GORDON R. CUMMING* \\ From the Department of Medicine and the Cardiac Laboratory, Children's Hospital of Winnipeg and the University of
Manitoba
}

Received July 16, 1962

Several recent publications have shown that changes in heart murmurs after the inhalation of amyl nitrite may be of diagnostic aid (Vogelpoel et al., 1959; Barlow and Shillingford, 1958). The effect of amyl nitrite on intracardiac hæmodynamics and intracardiac heart sounds has been studied extensively by Vogelpoel et al. $(1960,1961)$ and Schrire et al. (1961). For the past four years amyl nitrite has been used in this laboratory as a diagnostic aid in the course of heart catheterization studies. Dye dilution curves obtained before and after amyl nitrite are of diagnostic value in certain situations and form the basis of this report.

\section{METHODS}

Cardio-green dye was used in all cases. The heart catheters were of the side hole type as selective angiocardiograms were obtained during the study of most patients. The dye curve was inscribed on a Sanborn 150 series recorder, blood being drawn from the femoral artery through a densitometer or cuvette of the Waters type by a motor-driven syringe at $19.4 \mathrm{ml}$. per minute. Two ordinary breaths of amyl nitrite were taken while monitoring arterial pressure. No attempt was made to give additional amyl nitrite. As soon as the arterial blood pressure started to fall, the stop-cock on the arterial cannula was switched to allow blood to flow through the densitometer. The dye was injected as soon as a steady base line was reached, and intracardiac pressures were then obtained through the heart catheter. All diagnoses have been confirmed by standard heart catheterization data and angiocardiography, and in many instances confirmation was also obtained at open heart surgery. Over 200 patients ranging in age from 3 weeks to 65 years have been studied in this way.

\section{RESULTS}

The dye curves were inscribed according to the convention of Hetzel, Swan, and Wood (1959). Examples of the dye dilution curves obtained before and after amyl nitrite in patients with various types of congenital heart disease are presented in Fig. 1 to 5. Typical cases have been selected. Any exceptions will be mentioned in the text. In all figures the control dye curve is inscribed above, and the curve immediately following amyl nitrite is inscribed below.

1. Small Left-to-right Shunts (Fig. 1). Amyl nitrite reduced the magnitude of all small left-toright shunts. If the systemic pressure was lowered sufficiently, the early recirculation hump on the dye curve, which is due to the left-to-right shunt, was obliterated (Fig. 1A). This was found to be true for all shunts at all levels-atrial, ventricular, and aorto-pulmonary. No exceptions have been encountered.

2. Large Left-to-right Shunts (Fig. 2). The large area under the recirculation hump representing the left-to-right shunt was reduced in nearly all patients by the amyl nitrite. Occasionally with severe pulmonary hypertension, a slight right-to-left shunt was produced with shunts at ventricular and aorto-pulmonary levels (Fig. 2C); this was never large. The left-to-right shunt through atrial

* Supported in part by the Manitoba Heart Foundation. 


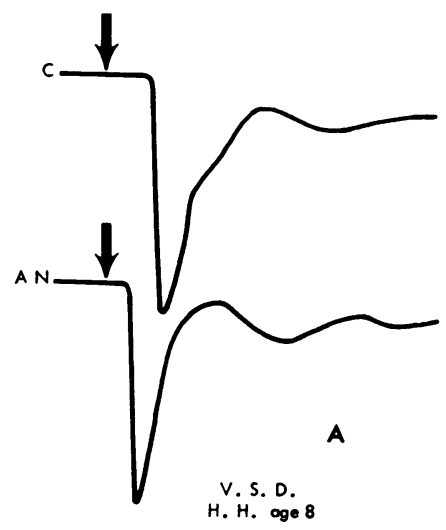

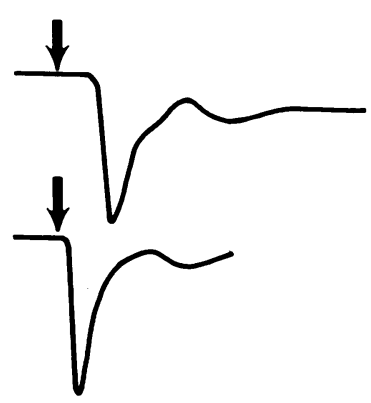

B

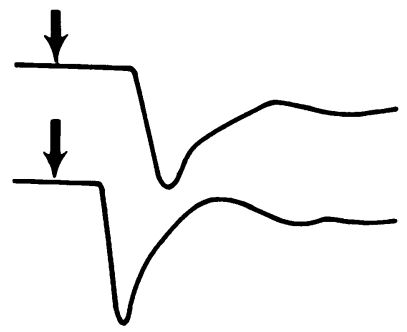

c

A. S. D.

P. D. A.
J. M. oge 5

FIG. 1.-Small left-to-right shunts. $\mathrm{C}=$ control; $\mathrm{AN}=$ amyl nitrite; arrow $=$ time of dye injection; V.S.D. =ventricular septal defect; A.S.D. =atrial septal defect; P.D.A.=patent ductus arteriosus; P.S. = pulmonary stenosis; P.F.O.=patent foramen ovale. Sites of injection(A) right ventricle; (B) inferior vena cava; (C) pulmonary artery. In each case the top curve is the control, and the bottom curve was obtained immediately following amyl nitrite inhalation.

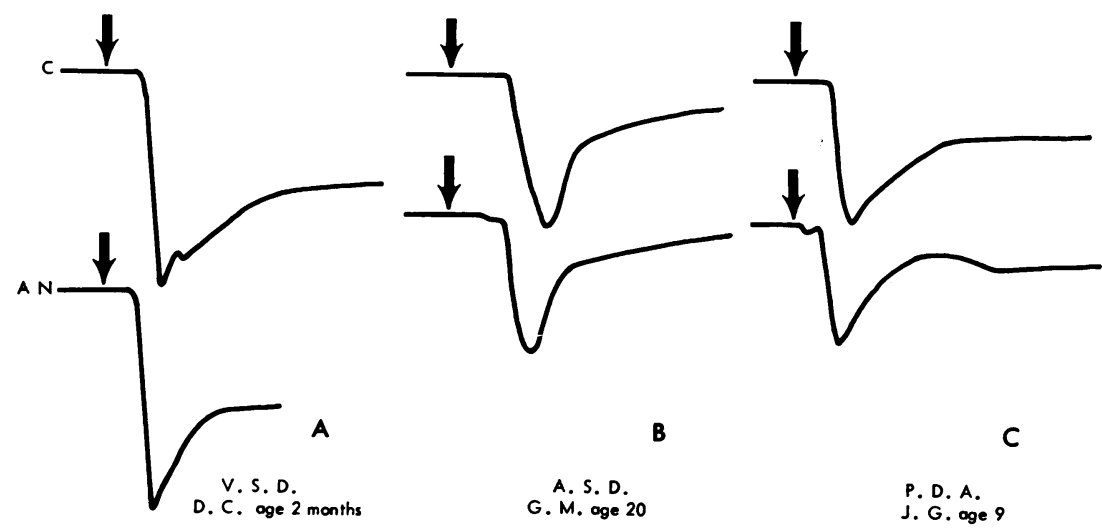

FIG. 2.-Large left-to-right shunts. Lettering as in Fig. 1. Sites of injection-(A) right ventricle; (B) inferior vena cava; (C) pulmonary artery.

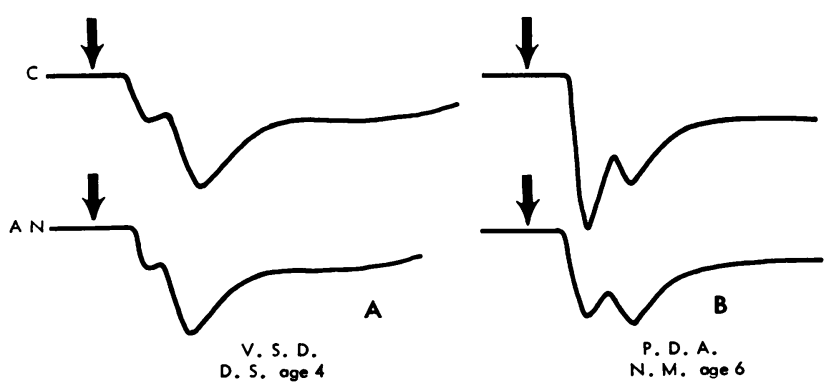

Fig. 3.-Large defects with high pulmonary vascular resistance. Lettering as in Fig. 1. Sites of injection-(A) right ventricle; (B) pulmonary artery. 


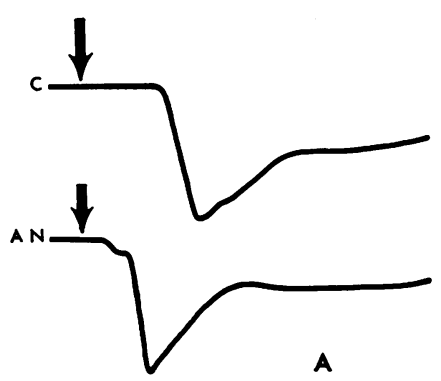

A. S. D.

D. B. oge 5
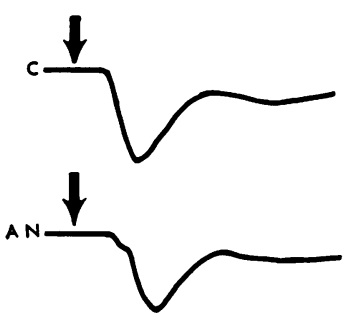

D

P. F. O.

C. O. oge 1 month

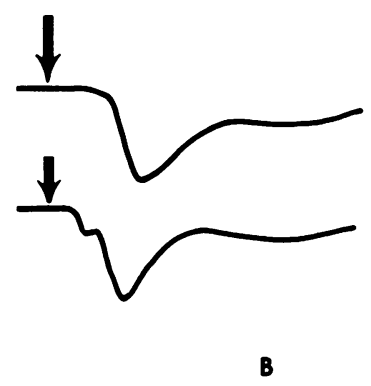

P. S. + A. S. D.

S. B. $\infty$

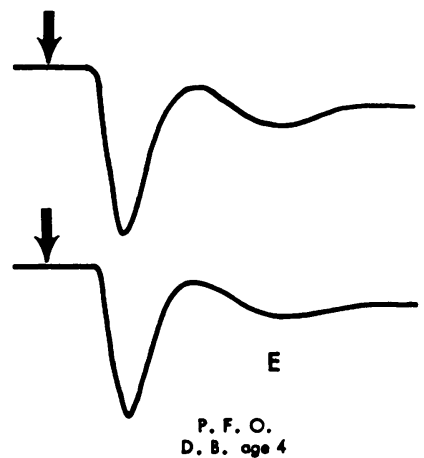

P. F. O.

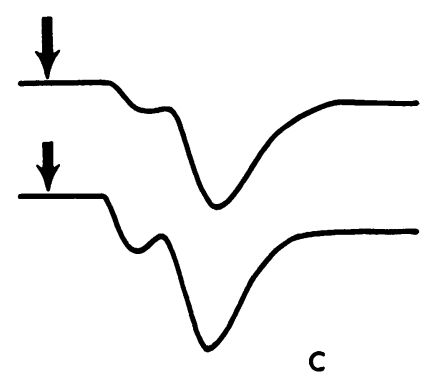

A. S. D. + sovere P. S S. W. age 42

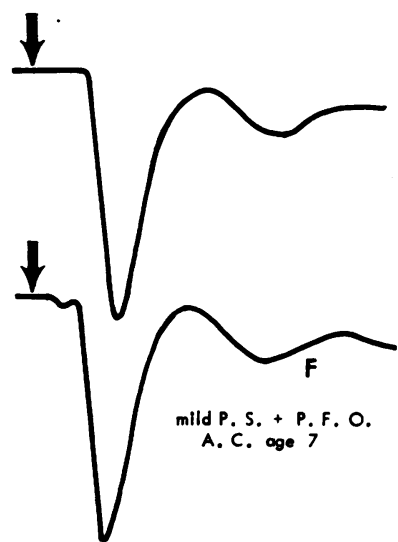

Fig. 4.-Right-to-left shunts at the atrial level. Lettering as in Fig. 1. All injections made into inferior vena cava.

septal defects was diminished in the majority, but in a few instances ro change in the size of this type of shunt was produced by the amyl nitrite.

3. Large Defects with Increased Pulmonary Vascular Resistance (Fig. 3). Increased pulmonary vascular resistance has not been encountered in any of the 70 patients with atrial septal defects who have had catheter studies in this laboratory. In patients with Eisenmenger's complex (ventricular septal defect with high pulmonary vascular resistance and right-to-left shunt), amyl nitrite did not produce large changes in the magnitude of the right-to-left shunts. In some instances, this shunt was slightly decreased, and in others slightly increased by the amyl nitrite. In patients with patent ductus arteriosus, pulmonary hypertension, and shunt reversal, similar findings were obtained.

4. Right-to-left Shunts at Atrial Level (Fig. 4). Most patients with uncomplicated atrial septal defects of secundum type, have small right-to-left shunts, as revealed by dye dilution curves obtained following the injection of indicator dye into the inferior vena cava. In most patients with atrial septal defects, this small right-to-left shunt could be increased by amyl nitrite. In some patients in whom there was no right-to-left shunt under resting conditions, amyl nitrite produced a right-to-left shunt (Fig. 4). However, in some patients an existing small right-to-left shunt was unchanged and in a few others a small right-to-left shunt present under control conditions was abolished by the amyl nitrite.

Three patients who had a patent foramen ovale with a competent flap and normal hearts have been studied by this method. The presence of a patent foramen ovale was proven by passage of a heart catheter from the right atrium to the left atrium. That this was not an atrial defect was proven by the absence of a shunt on angiocardiography (injecting into left atrium), and the presence of left atrial pressures at least $5 \mathrm{~mm}$. $\mathrm{Hg}$ greater than the right atrial. No left-to-right shunt was observed 
on the dye dilution curves or with oximetry studies. In two of these patients, amyl nitrite inhalations did not cause any right-to-left shunt (Fig. 4D). However, in one an early appearance of dye was observed indicating a right-to-left shunt (Fig. 4E) through the normal foramen ovale. This patient was a 1-month-old infant.

When pulmonary stenosis exists with a true atrial defect, the direction of the shunt across the atrial defect is determined by the severity of the pulmonary stenosis and the functional capacity of the right ventricle. In the patients with a left-to-right shunt only, the direction of the shunt may be reversed following amyl nitrite and may become entirely right to left. In the patient shown in Fig. 4B the shunt was predominantly left to right under resting conditions and predominantly right to left after amyl nitrite. In patients with severe pulmonary stenosis and atrial septal defects, large right-to-left shunts at the atrial level may be further increased by amyl nitrite as seen in Fig. 4C.

In many patients with mild valvular pulmonary stenosis probe-patency of the foramen ovale can be demonstrated by passage of a heart catheter. When the right atrial pressures become raised, a right-to-left shunt may occur through this foramen ovale. Under ordinary resting conditions there may be no shunt through the foramen ovale as shown by oximetry and also confirmed by dye dilution curves. However, following amyl nitrite the dye dilution curve may show an early appearance of a small amount of dye indicating a right-to-left shunt through the foramen ovale. The severity of the pulmonary stenosis did not influence this change and some patients with small gradients across the pulmonary valve did show right-to-left shunts through a foramen ovale after amyl nitrite. The right ventricular pressure in the patient shown in Fig. $4 \mathrm{~F}$ was only $40 \mathrm{~mm}$. $\mathrm{Hg}$ under resting conditions. Dye dilution curves, however, do not always show a right-to-left shunt when a foramen ovale is present in patients with valvular pulmonary stenosis. Two patients have been studied where no shunt was present at rest or after amyl nitrite, and yet it was possible to place the catheter across the foramen ovale.

5. Right-to-left Shunts at Ventricular Level (Fig. 5). In patients with tetralogy of Fallot and a moderate degree of cyanosis, amyl nitrite caused an increase in the already existing severe right-toleft shunt. This is shown in Fig. 5A. In patients with tetralogy of Fallot and lesser degrees of cyanosis, the amyl nitrite allows a small shunt to be easily detected. In the patient whose dye curves appear in Fig. 5B, arterial oxygen saturation was 93 per cent, and the right-to-left shunt was very small in the control dye dilution curve. However, following amyl nitrite the right-to-left shunt was considerably increased and easily detected.

Several patients have been studied in whom varying degrees of infundibular stenosis exist in the presence of ventricular septal defects, but with shunts under resting conditions entirely in a left-toright direction. Under such circumstances, amyl nitrite may completely reverse the direction of a shunt, changing the left-to-right shunt to a right-to-left shunt. This is well shown on the dye curves presented in Fig. 5C and D. Finally, some patients have been encountered in whom conventional studies of oximetry, pressure records, dye curves, and angiocardiography fail to show any lesion other than infundibular pulmonary stenosis. The right ventricular pressures in these cases were equal to systemic, and the pressure curves in the right ventricle did not have peaked apices, so that there were strong suspicions that ventricular defects might be present. However, oxygen determinations and dye dilution curves under resting conditions did not give any clue to the presence of such a defect. In such cases, amyl nitrite inhalation has caused a right-to-left shunt to appear on the dye dilution curves. Two examples are shown in Fig. 5E and F. The control curves do not show any early appearing dye, indicating the absence of a right-to-left shunt, whereas following amyl nitrite the presence of an anatomical short-cut between the right and left sides of the heart is clearly revealed.

In most instances a dye dilution curve was also obtained five minutes after the amyl nitrite inhalation, and this curve was usually exactly similar to the control curve obtained before giving the drug. While spontaneous variations in the contour of dye dilution curves do occur, such would not seem to explain the observed changes. In one subject with a very high pulmonary vascular resistance associated with a large patent ductus arteriosus the amyl nitrite produced a drop in blood 

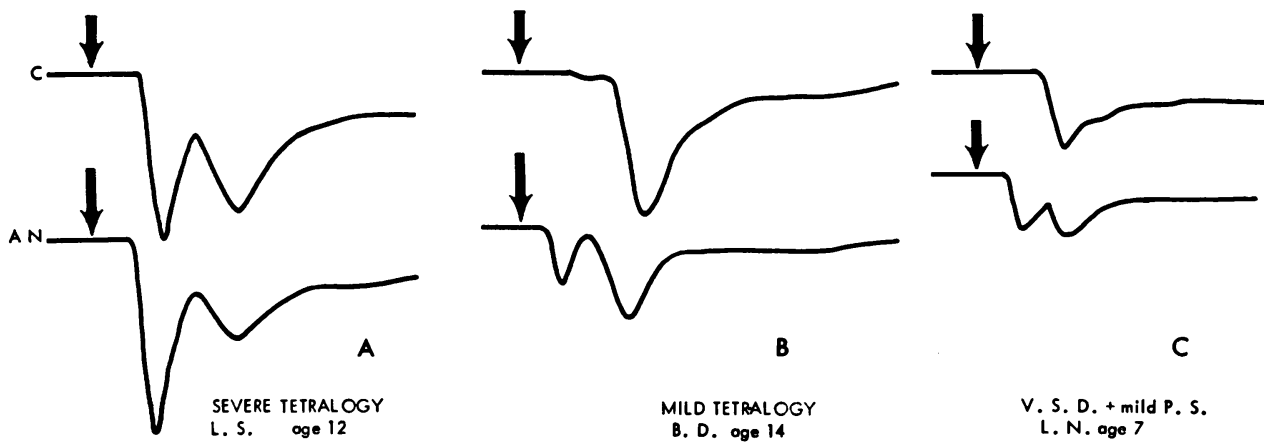

pressure lasting beyond a few minutes, considerable cardiac slowing, and signs of anoxia. Administration of atropine and oxygen corrected the difficulties. While other patients complained of the odour or of the flushing produced by the amyl nitrite, there were no notable side-effects.

\section{DisCUSSION}

Amyl nitrite causes a sharp drop in arterial blood pressure which lasts from 30-120 seconds after its inhalation. This is due to peripheral vascular dilatation. The cardiac output in the first minute following administration of amyl nitrite is invariably increased. The speed of the circulation is accelerated and this is quite apparent in the dye dilution curves.

A decrease in aortic and left ventricular systolic pressure would be expected to cause a decrease in the magnitude of left-to-right shunts in patients with ventricular septal defects and patency of the ductus arteriosus. Such proved to be the case. In theory, it was not expected that amyl nitrite would alter dynamics at the atrial level sufficiently to change the magnitude of left-to-right shunts through atrial septal defects. However, in most instances it was found that shunts across atrial septal defects were changed just as much as shunts across ventricular septal defects by the inhalation of amyl nitrite, and it is thus not possible to differentiate the level of left-to-right shunts by this response. Also, it is not possible to judge the level of right-to-left shunts by the response to amyl nitrite with a single injection of indicator dye into the inferior vena cava. In patients with pulmonary stenosis, existing right-to-left shunts were increased or could be made to appear whether the communication between the right and left sides of the heart was at the atrial or at the ventricular levels. 
However, serious increases in right-to-left shunts were produced by amyl nitrite only in the presence of pulmonary stenosis.

Conversely, when pulmonary stenosis was absent, despite the presence of systemic or near systemic pressures in the right ventricle, amyl nitrite did not cause much change in the size of right-to-left shunts.

The most important application of these findings lies in the detection of ventricular septal defects when pulmonary stenosis is present, and there is little or no shunt across the defect because the pressures in the ventricles are balanced. If the pulmonary stenosis is repaired by operation, leaving a ventricular septal defect, a large left-to-right shunt is suddenly produced, and this may lead to pulmonary congestion and severe heart failure. The pre-operative recognition of the defect is of extreme importance in such cases. After amyl nitrite inhalation dye dilution curves obtained with the injection of indicator dye into the right ventricle have shown a clear-cut right-to-left shunt in all patients with ventricular septal defects associated with pulmonary stenosis. This occurs whether the stenosis is valvular or infundibular. In one patient with pulmonary stenosis a dye dilution curve after amyl nitrite suggested the presence of an associated ventricular septal defect though selective angiocardiography from the right ventricle showed no defect other than pulmonary stenosis: an $8 \mathrm{~mm}$. ventricular septal defect was found at operation.

When a large enough right-to-left shunt is produced, the change in arterial oxygen saturation may be seen either with a cuvette type of oximeter or indirect ear-piece oximetry. However, small shunts may be missed in this way, and the method is not selective in telling whether the defect is at atrial or ventricular level.

The second useful application of dye curves after amyl nitrite arises when it is not possible to catheterize the pulmonary artery in patients with moderate to large ventricular septal defects. If the amyl nitrite inhalation produces a large right-to-left shunt where little or none was present before, then in all probability pulmonary stenosis is present. This has value in judging the operability of patients who have developed smaller hearts and clear lung fields after previously having had pulmonary plethora. This may be due to severe pulmonary vascular disease, but may also be due to the development of infundibular pulmonary stenosis as pointed out by Gasul et al. (1957).

Amyl nitrite inhalation will cause a large increase in any right-to-left shunt if pulmonary stenosis is present, and little change in the absence of pulmonary stenosis.

Finally, the occasional patient in severe heart failure in infancy may benefit from pulmonary plication to reduce pulmonary flow as a palliative procedure before the patient reaches a size to permit safe open heart surgery. If infundibular pulmonary stenosis has developed, this procedure would not be indicated. Recently, an infant in severe heart failure was shown to have a large ventricular defect with a pulmonary flow of over twice systemic. Both venæ cavæ joined the coronary sinus, and it was not possible to place the heart catheter beyond the inflow area of the right ventricle. No right-to-left shunt was present on dye dilution curves obtained at rest, but after amyl nitrite a 20 per cent right-to-left shunt resulted. In the light of our previous experience this suggested infundibular pulmonary stenosis, and at heart operation a gradient of $30 \mathrm{~mm}$. across the right ventricular outflow tract was demonstrated.

The purpose of this report has been to show where amyl nitrite may be of help in the cardiac laboratory during heart catheterization studies. The important changes on the dye dilution curves are evident on inspection alone. Quantitative aspects of these changes in intracardiac shunts and pressures will form the basis of a subsequent report.

\section{SUMMARY}

Hæmodynamic changes following amyl nitrite inhalation have been assessed in patients with congenital heart disease by means of indicator dilution curves. All left-to-right shunts are diminished and most right-to-left shunts are increased by amyl nitrite. However, the greatest changes occur in patients with pulmonary stenosis. In some patients with pulmonary stenosis and ventricular septal defect with left-to-right shunts at rest, amyl nitrite causes a reversal of the shunt to one 
that is entirely right to left. In the patient with pulmonary stenosis and a ventricular septal defect with balanced ventricular pressures, and no demonstrable shunt by conventional techniques, a dye dilution curve after amyl nitrite inhalation will show a right-to-left shunt and reveal the presence of the defect. Large increases in the magnitude of right-to-left shunts were only observed in the presence of pulmonary stenosis.

\section{REFERENCES}

Barlow, J., and Shillingford, J. (1958). The use of amyl nitrite in differentiating mitral and aortic systolic murmurs. Brit. Heart J., 20, 162.

Gasul, B. M., Dillon, R. F., Vrla, V., and Hait, G. (1957). Ventricular septal defects: their natural transformation into those with infundibular stenosis or into the cyanotic or noncyanotic type of tetralogy of Fallot. J. Amer. med. Ass., 164, 847.

Hetzel, P. S., Swan, H. J. C., and Wood, E. H. (1959). Intra Vascular Catheterization, ed. H. A. Zimmerman, p. 539. Thomas, Springfield, Illinois.

Schrire, V., Vogelpoel, L., Beck, W., Nellen, M., and Swanepoel, A. (1961). The effects of amyl nitrite and phenylephrine on the intracardiac murmurs of small ventricular septal defects. Amer. Heart J., 62, 225.

Vogelpoel, L., Nellen, M., Swanephoel, A., and Schrire, V. (1959). The use of amyl nitrite in diagnosis of systolic murmurs. Lancet, $2,810$.

-, Schrire, V., Beck, W., Nellen, M., and Swanepoel, A. (1961). The atypical systolic murmur of minute ventricular septal defect and its recognition by amyl nitrite and phenylephrine. Amer. Heart J., 62, 101.

,$- \frac{1}{-}$, Nellen, M., and Swanepoel, A. (1960). The use of phenylephrine in the differentiation of Fallot's tetralogy from pulmonary stenosis with intact ventricular septum. Amer. Heart J., 59, 489. 